\title{
The Political Economy of Long-Term Fiscal Planning from a Social Democratic
} Perspective

Long-term fiscal projections

Great care and intellectual power have gone into the process of producing the Treasury's 2013 long-term fiscal projections. ${ }^{1}$ Those projections will, no doubt, create some controversy.

The assumptions will be open to challenge, as will, even more so, some of the policy conclusions that the Treasury may draw from the exercise. Yet no one should be in doubt that this process has been a much more open and considered one than its predecessors. I enjoyed participating in the Treasury's Long-Term Fiscal External Panel and have been impressed by the calibre of the officials involved. ${ }^{2}$

To engage in producing long-term fiscal projections which push out the forecasts of revenue and expenditure 50 or even 100 years might seem an exercise in either hubris or self-delusion, given the inevitable frailty of whatever assumptions are made. That is especially so when we remember that fiscal forecasts are often well in error even after as short a period as

one year, let alone 50. Moreover, both the technical assumptions and any assumed policy responses to developing issues are, of course, deeply intermeshed with the realities of politics, as well as the changing nature of the surrounding society and economy. Most political discourse occurs within a relatively short time frame, which is not simply a function of the electoral

The Hon Dr Sir Michael Cullen is the Chair of New Zealand Post Ltd and was formerly Minister of Finance and Deputy Prime Minister in the Labour-led governments between 1999 and 2008. In 2012-2013 he was a member of the Treasury/Victoria University of Wellington Long-Term Fiscal External Panel. cycle. The self-interest of individuals and groups frequently creates barriers to sustaining a longer-term focus.

In the modern world of general political debate a healthy scepticism has been replaced all too often by a pervasive low-grade cynicism which attributes base motives to nearly all activities (except those of political commentators, bloggers and the like, of course). In such a world any of the conclusions arising out of such an exercise as this are too easily sensationalised and/or dismissed as we return to discussing whatever the immediate itch of the day is. And if the possible conclusions of the exercise look too worrying, then people may simply turn away and avoid them since it is all well into the future anyway. Most importantly, most people have enough to worry about already and just want to get on with their lives. We always have to remind ourselves that 'policy wonks' are not the normal run of humanity, any more than monks were in the Middle Ages. Given those realities, it is not surprising that the attitude of many politicians can be summed in that famously apocryphal saying: 'What has posterity done for me?' Or, as the prime minister of Luxembourg recently put it, 'We all know what to do, we just don't know how to get re-elected after we've done it.' 
Despite all of these issues, this is no reason to give up. The exercise of producing long-term fiscal projections is an important one which may yet contribute to intelligent debate about some of the long-term challenges we face as a nation and how best to meet them. The projections are not a prediction of what will actually happen. They are projections of what would happen if certain reasonable assumptions based largely on current policies, economic assumptions around growth, inflation major fiscal adjustment to a crisis in the last generation or so in which those at the bottom of the heap, and those in the middle, did not come out a lot worse off than those at the top. Revolutions can be different - but these are not envisaged in the Treasury's long-term projections.

In the nature of things such drastic adjustments are seldom well thought through, and are driven by a 'crash through or crash' mentality which pays little regard to the human consequences, or even to evidence-based policies

\section{... we should not leave to our children and grandchildren harder choices than we are prepared to make ourselves.}

and so on and demographic trends are allowed to flow through into the fiscal numbers. We may question some of those assumptions, but it would be a foolish person who would argue that any of them are unreasonable. The results therefore need to be taken seriously.

\section{Fiscal adjustment from a social democrat perspective}

The main, and entirely expected, conclusion of the long-term fiscal projections is that on the current path New Zealand will eventually experience an unsustainable increase in the level of government debt which will, presumably, require drastic corrective action, either voluntarily or imposed from without. From the perspective of a social democrat this matters deeply. At one level it matters because such crises usually mark a significant loss of economic sovereignty, as we are seeing in parts of Europe at the present time.

For me, this is less important than for some social democrats since absolute economic sovereignty in the modern world is perhaps no more than an illusion. What is more important is what happens in such rapid adjustments to a fiscal crisis. The distributional consequences are nearly always severe and can often be long-lasting. It would be hard to find a as opposed to ideologically-driven ones. There are people who glory in the possibilities of such crises, casting themselves in the role of a kind of fiscal Abraham Lincoln remarking that the occasion is piled high with difficulty. They need reminding that that was in the context of a brutal civil war.

The conclusion I would draw from this is two-fold. The first part is that we should not leave to our children and grandchildren harder choices than we are prepared to make ourselves. The second part is that gradual adjustment over time is preferable to big bang pyrotechnics, however much that may appeal to the odd 'pyrotechnician'. It is far more likely that most people, particularly the more vulnerable, will be able to cope under a scenario of gradual adjustment, especially if transitional assistance is provided where desirable. Moreover, the Treasury's projections also say that gradual adjustments over time should be sufficient to avoid any kind of doomsday scenario.

At a deeper level this all matters because for social democrats the twin concepts of security and opportunity lie at the base of political thought and action. It does not take much consideration to see that a policy of allowing a crisis to develop over a long period of time which then forces drastic corrections is antipathetic to such values. Security is obviously threatened, but so too for many is opportunity. Even in New Zealand we can still see in such places as Murupara and Minginui the results, 25 years on, of rapid change unaccompanied by wellmanaged transitions.

Thus, there is an inherent conflict likely between the longer-term focus, which is likely to be welfare-maximising from a social democratic perspective, and what might be called the mañana principle which tends to dominate much political discourse: never do today what you can put off until tomorrow. This is even more so in the very areas that are central to the long-term fiscal challenges: health and retirement income.

Health, education, income transfers and the justice sector

Health

This brings me to a few comments on the Treasury's projections themselves and some of the assumptions underlying them. In the case of health, the historic trends in the growth of expenditure are clear. What is also clear is that attempts to deviate sharply from those trends have fairly quickly come unstuck. In the early 1990s, for example, strong constraint on spending growth led in the first instance to the growth of deficit spending, or what came to be called the 'second chequebook'. This was followed by a significant expansion of the budget allocation which put public health expenditure back on the trend line. The same process occurred with greater rapidity in the early 2000 .

The combination of demographic transition, new drugs and procedures, rising expectations, and international competition for staff all point to inexorable upward cost pressures in the health sector. Stronger economic growth may help with the costs of staff pressures, but will at least in part be offset by the relationship between health spending and gross domestic product (GDP) per capita. And for those tempted in that direction, there is little evidence that shifting spending to the individual actually saves much for the government, while it all but ensures greater inequality of outcomes. In the absence of remarkable changes 
in health technology, which cannot be discounted, it seems probable that the fiscal risks are still on the upside from current projections.

Because this is an area with so much uncertainty it is also one in which it is nigh on impossible to think in terms of specific long-term pre-funding or insurance approaches. Given that there is always unmet need, or at least unmet demand, any surpluses built up in advance would come under intolerable pressure to be spent. My rather dismal conclusion is that the best we can aspire to is to try to restore a greater emphasis on public and preventative health, in particular spending on the young and the most disadvantaged. That is already increasingly difficult because of the ageing of the population. What is often forgotten, somewhat surprisingly, is that the demographic transition is also an electoral transition. Given the quite strong correlation between age and the propensity to vote, it is possible that the proportion of those actually voting who will be aged $65+$ will be as high as $40 \%$ by 2060 . If we divide the electorate into three blocks - 18-39, 40-64 and 65+ - the last will be possibly be the largest group of those voting and certainly the most focused on a narrow range of common interests.

To put it another way, a political party focused on the interests of the elderly will only need to capture about a fifth of the votes of that group to be in a powerful position as a power broker under a proportional electoral system such as mixed member proportional (MMP). It will thereby be able to protect the interests of the elderly, if need be at the expense of other groups.

\section{Education}

This might suggest that the Treasury's optimism that a demographic dividend will be able to be garnered from the spending on education due to the decreasing proportion of young people in the population is well founded. Indeed, the Treasury has suggested that the proportion of GDP spent on education could be reduced by increasing class sizes and shifting more of the cost of tertiary education to the individual. This reaffirmation of economics as the dismal science is to be expected, if disappointing.

In my view, the projected 'demographic dividend' in education ignores some powerful countervailing factors. The next half century will see increasing competition to improve both the quality and quantity of education. That will mean further time spent in education and further increases in participation rates at the most expensive end of the system. If
Rather, the rhetoric seems to be more about producing scary numbers about the long-term costs of current beneficiaries as a prelude to measures which are predominantly negative in relation to beneficiaries. The simple and enduring truth is that the most effective way of cutting the costs of benefits is to reduce unemployment, but not at the cost of a race to the bottom in terms of wages and conditions.

\section{The Treasury data is quite clear that the level of increase in revenue as a proportion of GDP needed over the next 50 years to keep within a reasonable debt constraint, however defined, is well within the levels reached within the last ten years.}

we are to seek greater efficiencies, a more positive approach to education would be in taking a more active role in ensuring that the skills we produce better match the opportunities available while avoiding the trap of an overly narrow vocational approach to education.

\section{Income transfers and justice}

Before turning to the two areas where I see the greatest opportunities for gradual long-term fiscal correction, let me touch verybriefly on income transfers and justice. The former will continue to be significant for the simple reason that we cannot foresee an economic transformation which will change the tendency of a market economy under conditions of rapid technological development to create widening income gaps. Those developed countries with greater equality of outcomes maintain much higher revenue and expenditure levels than seem to be acceptable in New Zealand.

As for justice, we may reap a demographic dividend but only if two things happen. One is a move away from the last generation's desire to see an ever more punitive system. The second is a very large upfront investment in remedial measures, which, despite some rhetoric, there is no sign of being implemented.
The greatest opportunities for long-term fiscal adjustment: raising revenue and retirement income provision

That leaves two big areas: retirement income provision and revenue. For some the latter remains an ideological no-go zone, a slough of despond in which whole economies disappear, or at least, like some kind of science fiction stargate, enter from the First World and emerge into the Third. Perhaps it is time in New Zealand to abandon this kind of Tea Party silliness, which belongs in the realms of creationism and global warming rejection.

\section{Raising revenue}

The Treasury analysis tells us two things. The first is that while the Treasury still argues that there are strong reasons for believing that a higher level of revenue has a negative impact on economic growth, it has to accept that the empirical evidence for this is weak. The second reinforces the first. The Treasury data is quite clear that the level of increase in revenue as a proportion of GDP needed over the next 50 years to keep within a reasonable debt constraint, however defined, is well within the levels reached within the last ten years. Those levels are well below those of many other developed countries with higher GDP per capita than New Zealand. 
Such an increase can be achieved in a number of ways. The easiest is by allowing for some element of 'fiscal drag', which is removed from the longterm fiscal projections. Simply assuming personal income tax brackets are adjusted upwards in line with the consumers price index (CPI) rather than GDP achieves substantially higher revenue to GDP over time, and indeed allows room for further ad hoc adjustments in tax brackets.

The second is by way of broadening out the tax base. We like to describe our system as broad-based, but in a number of ways the base has been narrowed over the last 20 years or so. Obviously, capital gains tax is one option. The Treasury favours a land tax for efficiency reasons, but I have grave doubts about its practicality given the resentment the expenditure side are heavily on the upside, I think that would be unwise.

\section{Retirement income provision}

This brings me to the one large remaining area: the funding of retirement income provision. Clearly, there is any number of ways of specifying the objectives of retirement income policy. I think nearly all social democrats would begin with the desire to ensure security; that is, to take away the fear of poverty in old age. Along with that, economic considerations would suggest that the nature of state support should, at the very least, not discourage savings or continued participation in the labour market. This is essentially the opportunity element. The third element would be fiscal sustainability; the fourth

\section{It is worth [noting] that the Australian \\ superannuation scheme is both compulsory and $9 \%$ of income, soon to rise to $12 \%$, paid for by a payroll tax on employers ... [h]owever, the Australian scheme ... can be withdrawn as a lump sum and all spent.}

that local body rates already cause. There is also the very considerable problem that it shares with a tax on unrealised capital gains that the amount due may bear a small relation to the ability to pay.

Greater use of 'hypothecated taxes', such as taxes tagged to particular spending areas, like health expenditure, could also be considered, since these may be regarded differently by people than other forms of taxation given a direct relation to benefits they can expect to enjoy. It would be interesting to look further at the considerable overseas experience with hypothecated taxes in that regard.

The essential point is that there is ample scope to close at least part of the longer-term gap between revenue and expenditure on the revenue side. It is tempting to suggest it all could be, quite easily, based on the Treasury projections. However, given my view that the risks on broad societal acceptance of the fairness and durability of the arrangements; and the fifth as much simplicity as possible.

Obviously there may be trade-offs between these elements. New Zealand Superannuation $(\mathrm{NZS})^{3}$ scores well on poverty avoidance and simplicity and reasonably on savings and labour market participation. Any changes should preserve these as much as possible. But it scores much less well on fiscal sustainability and societal acceptance of durability.

Various proposals have been made to address this situation, particularly raising the age of eligibility for NZS; lowering the level of payment over time, in particular by changing the indexation measure from wages to prices; or reintroducing some form of income testing. Of these, only raising the age of eligibility for NZS meets the criteria I have outlined. With life expectancy continuing to rise, some increase in the age of eligibility at some point seems inevitable. An initial phased increase in the age of eligibility for NZS with ample notice followed by periodic reviews seems the most sensible way to make this policy change and the most likely to win broad acceptance.

The other two suggestions, of lowering the level of the NZS payment or income testing the payment, have little merit. Any significant reduction in the relationship of NZS to other incomes will throw many elderly people below the poverty line. Its political half-life would be something under three years. In any case, the current relativity is not some tail on the donkey affair but well rooted in past experience and studies.

As for income testing, it did not survive the first MMP election and would not survive a future one. It clearly discourages work participation and savings, even more because an income test without an assets test, especially for the elderly, would not be very effective in reducing the cost of NZS.

\section{Option 1: Enhanced KiwiSaver scheme}

The most fruitful avenue to explore, other than raising the age of eligibility for NZS, is to reduce the cost of NZS without reducing the standard of living of the elderly. This change could be brought about through the interaction of an enhanced KiwiSaver scheme and NZS. ${ }^{4}$ It is worth beginning with the fact that the Australian superannuation scheme is both compulsory and $9 \%$ of income, soon to rise to $12 \%$, paid for by a payroll tax on employers. However, the Australian scheme is coming under criticism for the fact that while their pension is incomeand asset-tested, their compulsory superannuation can be withdrawn as a lump sum and all spent. Now that the schemeis maturing, the dynamicinstability this creates is becoming obvious.

New Zealand's current arrangements present the same issue in a different way: KiwiSaver may make many more independent of NZS but has no impact on the cost of NZS. With the number of KiwiSavers already far higher than forecast, it is not a long step to make the scheme compulsory, tighten some of the criteria, and, over time, gear it up 
to a level far closer to that planned in Australia. At that point the relationship between KiwiSaver and NZS becomes one for serious discussion. As an example of what could be considered I have had a number of options modelled.

The models all start from KiwiSaver becoming compulsory from 1 July 2016, with all people signed up as they turn 18 and the opt-out provision on autoenrolment removed. All remaining adults would be enrolled on 1 July 2020. The contribution rates would be lifted back to $4 \%$ of income for employees, matched by $4 \%$ from employers, also from 1 July 2016. Employer contributions would then increase by half a per cent per annum until reaching either $8 \%$ in one set of models or $6 \%$ in the other. As a matter of practicality and individual affordability it may be desirable to begin new entrants on a lower personal contribution rate, say $2 \%$, and gear up over time, but as this has no significant impact on costs or effects over the long term it has been ignored in the modelling.

All of the modelling assumes that, however it is made up, retired people will continue to enjoy a guaranteed retirement income at least equivalent to that of NZS based on the current wage relativity formula. Two basic ways of reducing the fiscal cost over the long term of meeting this criterion have been explored. In the first, it was assumed that half of the accumulated KiwiSaver savings would have to be accessed by way of annuity. Where this was less than the guaranteed retirement income it would be made up to that level. In effect this means that for many people the shift from state funding to private funding would result in half of their KiwiSaver savings being income-tested away.

This could prove difficult to establish and maintain as an acceptable policy position, even though it would certainly have a substantial impact on the longterm fiscal costs of NZS. It also has the usual problems of applying an income test fairly. However, the fiscal outcomes are impressive. Under either higher contribution rate modelling the cost of NZS falls to under $2 \%$ of GDP by 2050 , all but vanishing by the end of the century. Remember, that is based on only $50 \%$ of
Figure 1: Enchanced KiwiSaver scheme

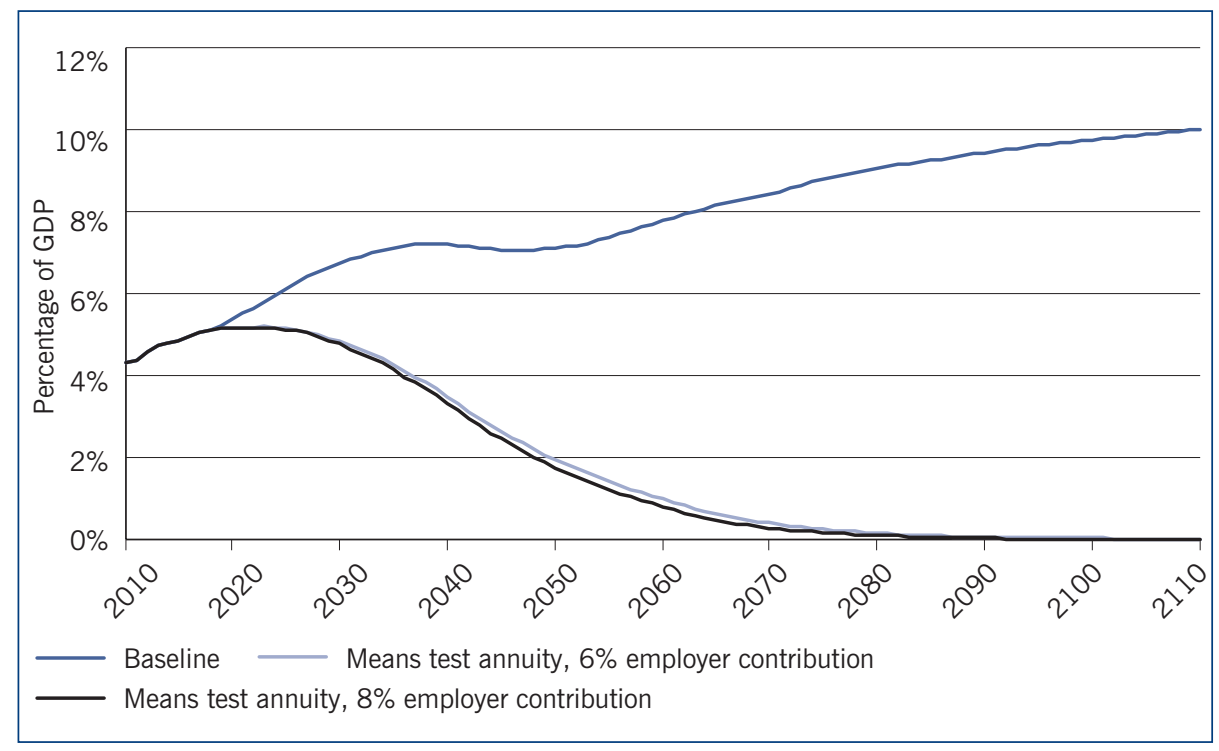

Figure 2: Tax on KiwiSaver withdrawals

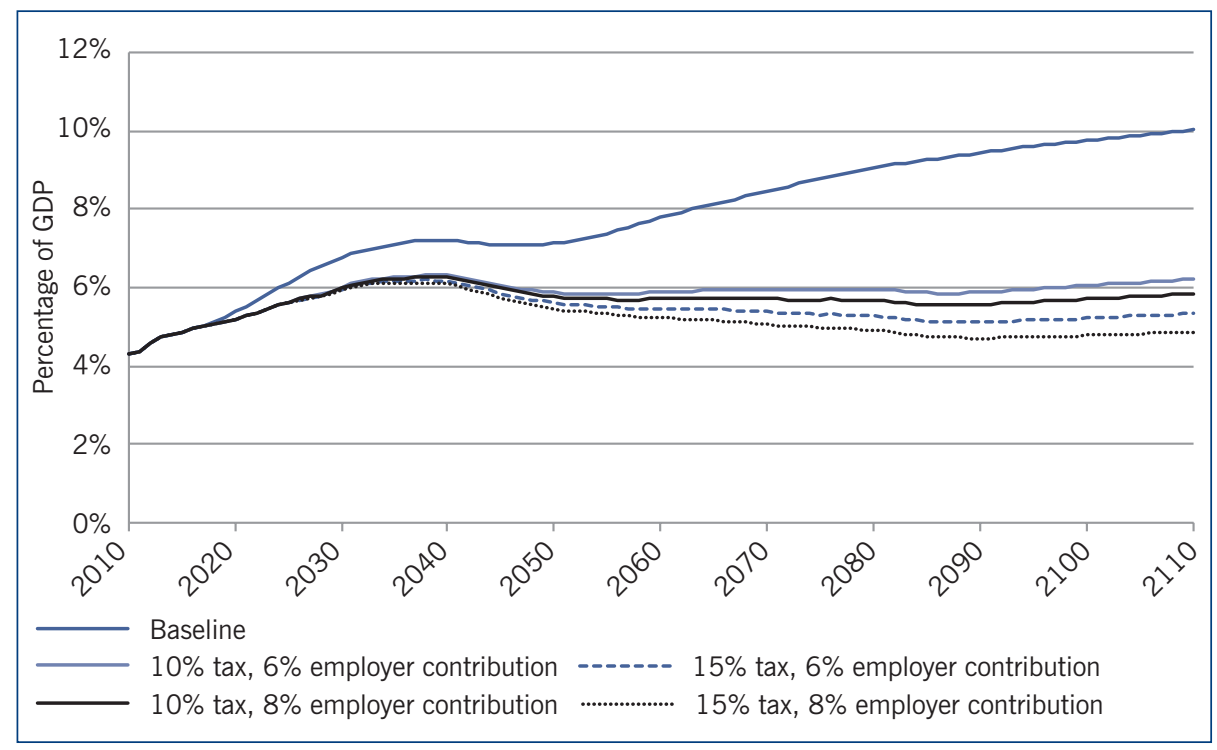

KiwiSaver accumulations being taken by way of annuity.

\section{Option 2: Tax on KiwiSaver withdrawals}

An alternative which has significant advantages in terms of simplicity and fairness is to deal with the KiwiSaver/ NZS interface on the revenue side rather than the expenditure side. Under this proposal, the current NZS scheme would be maintained as is, with the exception of an initial adjustment to the age of eligibility to 67 being phased in starting in, say, 2020. The revenue offset would come from a withdrawal tax being imposed on accumulated KiwiSaver savings of either $10 \%$ or $15 \%$. Currently, KiwiSaver is taxedtaxed-exempt, or 'TTE', which means that contributions come out of people's post-tax income, then the income those contributions earn while they are in the fund is taxed, but withdrawals are taxexempt. The new KiwiSaver withdrawal tax would apply to those permanently emigrating or to the accumulated savings at maturity (assumed to remain at age 65). The tax would only apply to accumulations starting with the introduction of the compulsory scheme. administratively much simpler than the first option and avoids the difficulties of income testing, but by the end of this century would reduce the projected net cost of NZS by about $5 \%$ or so of GDP, having kept that net cost at about $5 \%$ of GDP over the second half of the century. Could such a scheme be politically feasible?
Such a scheme would be 
The answer to that is that anything in this area is fraught with difficulty for obvious reasons. But it does seem to me to have at least as much chance of success as any of the other options that have been discussed publicly.

In order to establish a clear relationship with maintaining the affordability of NZS two simple changes could be made. One would be to name the tax 'NZS Tax'. The other would be to pay the proceeds of the tax directly into the New Zealand Superannuation Fund. ${ }^{5}$

Another change which would help secure confidence in the future of NZS would be to transfer the remaining state asset shares into a holding company owned by the New Zealand Superannuation Fund. This would, in effect, bring forward the resumption of government contributions, at a lower rate than previously, but also bring a welcome focus on long-term wealth creation with respect to the assets.
In the much longer term, some further increase in the age of eligibility for NZS beyond 67 will probably be required, but there is no reason to have to address that now or for some considerable time to come. I mentioned earlier that we should not leave to our children and grandchildren harder decisions than we are prepared to make ourselves. The reverse of that is that we do need to recognise their right to make some decisions and not try to predetermine posterity, even though, as we say, we can do more for posterity than it can do for us.

For me, the crucial point remains, as it has been for a long time, not just making NZS sustainable but convincing people that it is. For that, decisions do have to be taken before too long, despite the reluctance of decision-makers to make them.
1 The Treasury's 2013 long-term fiscal projections are available on the Treasury website: http://www.treasury.govt. nz/government/longterm/fiscalposition/2013.

2 For more information about the Treasury's Long-Term Fiscal External Panel see: http://www.victoria.ac.nz/sacl/about/ chair-in-public-finance/events/long-term-fiscal-external-panel.

3 New Zealand Superannuation is a fortnightly payment from the government for people aged 65 years and over. For further information about the policy see: http://www. workandincome.govt.nz/individuals/a-z-benefits/nzsuperannuation.html.

4 KiwiSaver is a voluntary work-based savings initiative. For further information about the policy see: http://www. kiwisaver.govt.nz/.

5 The New Zealand Superannuation Fund is a government fund that was established to partly pre-fund the future costs of NZS.

\section{Acknowledgements}

This article is adapted from a speech given to the Affording our Future conference held at Victoria University of Wellington, 10-11 December 2012. The author would like to thank Lucas Kengmana and Chris Ball from the Treasury for their assistance in modelling some of the policy suggestions made in the article.

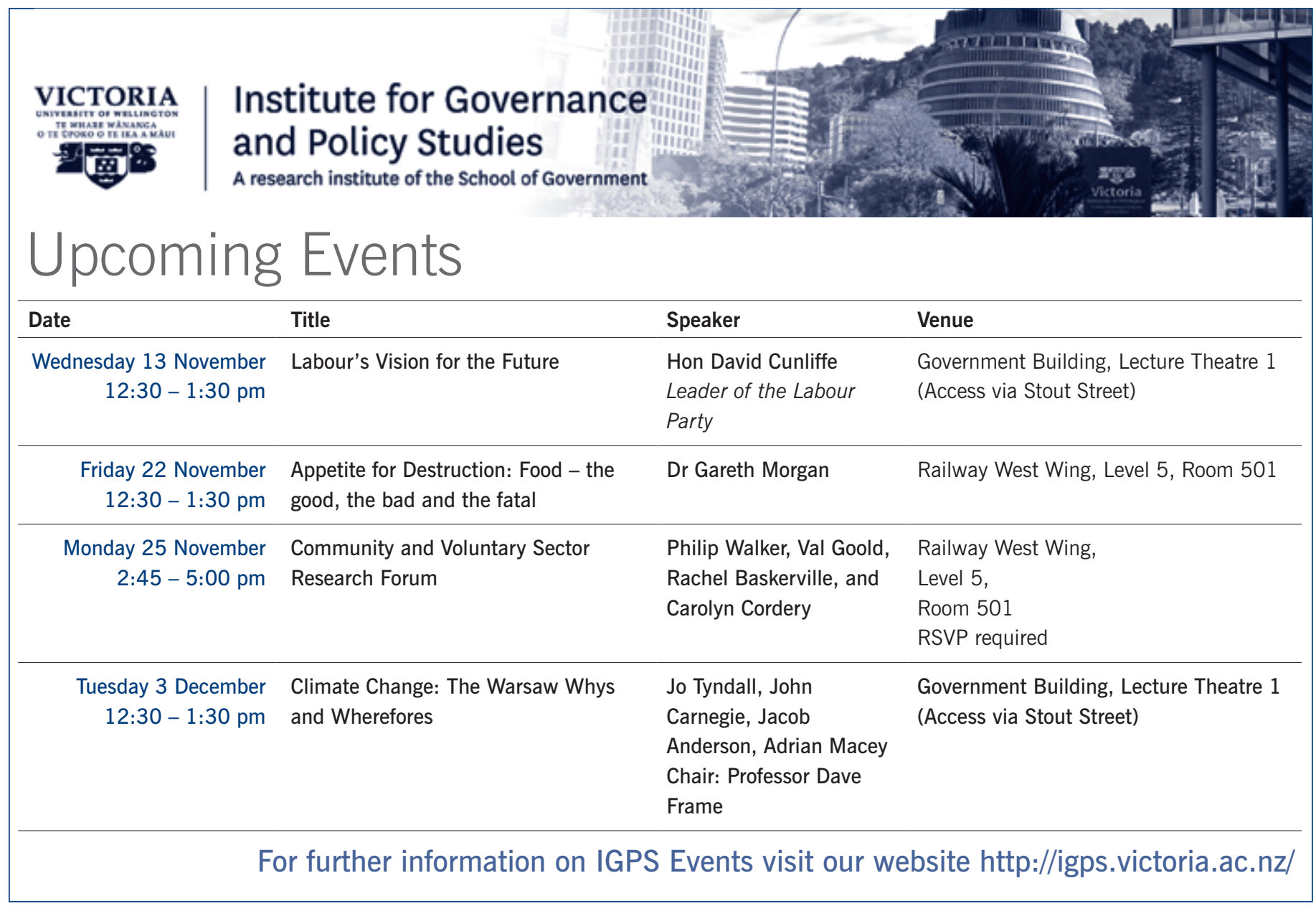

